\title{
A TOlerânCIA E OS Limites da LeI / THE TOLERANCE AND THE Limits OF LAW
}

\section{Vicente de Paulo Barretto ${ }^{1}$}

\begin{abstract}
Resumo
O objetivo do presente artigo é situar historicamente o significado da palavra "tolerância" na cultura ocidental. O artigo busca mostrar como correntes representativas do pensamento social moderno não consideram viável a concretização jurídica dessa virtude política nas democracias pluralistas.

Pretende ainda o artigo, discordando dessas correntes, investigar quais seriam as bases conceituais da nova tolerância, considerada como princípio social e político essencial para o funcionamento do Estado democrático de direito.
\end{abstract}

Palavras-chave: Tolerância. Cultura ocidental. Virtude. Estado democrático de direito.

\begin{abstract}
The purpose of this article is historically situate the meaning of the word "tolerance" in Western culture. The article seeks to show how representative tendencies of modern social thought does not consider viable legal embodiment of this political virtue in pluralistic democracies.

Still want the item, disagreeing with these currents, which would investigate the conceptual basis of the new tolerance, considered essential political and social principle for the functioning of the democratic state based on the rule of law.
\end{abstract}

Keywords: Tolerance. Western culture. Virtue. Democratic state based on the rule of law.

1. Introdução; 2. A evolução de uma ideia; 3. Uma relação conflituosa; 4. As aporias da tolerância liberal; 5. A ordem legal e o véu da intolerância;

\footnotetext{
${ }^{1}$ Doutor em Direito. Professor do Mestrado e Doutorado em Direito da UNESA. Professor visitante do PPG em Direito da UNISINOS. E-mail: vpbarreto@terra.com.br.
} 
6. A guisa de conclusão: tolerância e estado democrático de direito; 7. Referências.

\section{A tolerância e os limites da lei}

\section{Introdução}

As sucessivas guerras civis, a violência nas cidades e no campo, as diferentes formas de fanatismo religioso, os ódios raciais e os conflitos étnicos retratam uma civilização dividida internamente e ameaçada de extinção. A busca de soluções para esses problemas no final do século XX exige a reavaliação de alguns valores, considerados os alicerces da nossa civilização, entre os quais se destaca o valor da tolerância, e de como a ordem jurídica, tanto na sua elaboração como, principalmente, na sua aplicação acha-se comprometida por esses valores fundamentais. Torna-se necessário, portanto, que essa avaliação seja precedida pela recuperação dos diferentes sentidos assumidos por essa virtude política na história do Ocidente, e pelo entendimento de como os sistemas jurídicos, principalmente nos países da América Latina, por não terem incorporado valores como o da tolerância na práxis políticoinstitucional, terminaram por constituir-se em instrumentos de aprofundamento das diferenças socioeconômicas e da exclusão social.

Assim, pretendemos: situar historicamente o significado da palavra "tolerância" na cultura cívica do Ocidente, mostrar como correntes representativas do pensamento social moderno não consideram viável a concretização jurídica dessa virtude política nas democracias pluralistas; e, finalmente, discordando dessas correntes, investigar quais seriam as bases conceituais da nova tolerância, considerada como princípio social e político essencial para o funcionamento do direito e do regime democrático.

\section{A evolução de uma ideia}


A palavra tolerância advém do latim, tolerantia, tendo sido empregada por escritores na Antigüidade para significar a aceitação submissa e conformada diante da dor e da adversidade. O Dictionnaire de l'Academie Française (1694), em sua primeira edição, definiu a palavra "tolerance" como significando condescendência, indulgência diante daquilo que não podemos impedir. Durante o século XVI, a palavra tolerância começou a ser empregada preferencialmente para significar a permissão, particularmente quando dada pelo governo, da prática de culto religioso; a expressão referia-se, portanto, à aceitação da liberdade religiosa. O tema central do debate, que ocorreu no pensamento teológico, durante as primeiras décadas da Idade Moderna, no contexto da Cristandade dividida pela Reforma Luterana, residiu na questão se era permissível ou tolerável a convivência de duas ou mais religiões dentro de um mesmo estado cristão. A eventual permissão governamental, entretanto, não representava a aprovação ou mesmo a aceitação de uma religião não-oficial, como, aliás, fica bem claro na máxima da Paz de Augsburg (1555): cujus regio, eius religio. Cada estado conservava a sua própria confissão religiosa, que era a religião oficial, sem prejuízo, entretanto, do culto de outras confissões.

A prática da tolerância, portanto, surgiu no contexto interno da Cristandade, onde o catolicismo romano ou o protestantismo eram a religião do Estado; e referia-se ao estabelecimento de relações civis paralelas, que assegurassem a própria sobrevivência da sociedade, colocada em risco pelas guerras religiosas. Dessa forma, a idéia da tolerância - significando a aceitação das convicções dos outros - foi usada inicialmente nos debates teológicos - tendo sido empregada, posteriormente, no debate político - servindo como justificativa racional para o estabelecimento do pluralismo religioso dentro do Estado e da própria Cristandade. A discussão política ocorreu entre cristãos, que, apesar de não estarem unidos em torno de uma mesma igreja, não renunciavam à mensagem do Cristianismo. A tolerância, portanto, não tratava das relações entre cristãos e não-cristãos, mas servia como valor político, fundador de uma ordem jurídica que estabelecia os limites da convivência civil entre católicos romanos e protestantes; refletia, assim, não preocupações intelectuais, mas realidades sociais e políticas e tinha por objetivo o estabelecimento da pax civilis $^{2}$

\footnotetext{
${ }^{2}$ CHRISTIN, Olivier. La Paix de Religion, l'autonomisation de la raison politique au XVI e._siécle. Paris: Seuil, 1997. p. 21-45.
} 


\section{Quaestio Iuris}

O primeiro autor a defender esse ponto de vista e a sistematizar a questão, em termos filosóficos, foi John Locke nas cinco cartas sobre a tolerância - A Letter Concerning Toleration $(1688)^{3}$. O filósofo inglês sustentou o argumento de que a tolerância era uma permissão da qual deveriam beneficiar-se somente alguns cristãos, estando dela excluídos os católicos romanos, porque deviam obediência não à Coroa Inglesa, mas ao Vaticano, uma potência estrangeira. Os argumentos de Locke em favor da tolerância baseavam-se na idéia da separação entre a comunidade religiosa, a Igreja; e a comunidade política, o Estado, sendo que a tolerância seria um dos direitos civis do indivíduo a serem garantidos pela comunidade política.

Os limites da tolerância seriam definidos, no entendimento de Locke, pelos tribunais civis e se materializavam nos controles institucionais das práticas religiosas. Assim, por exemplo, Locke condenava a Inquisição Católica porque a seu ver a observação empírica demonstrava que não era uma política eficiente conseguir, pela força, a adesão de alguém a uma crença religiosa; isto porque o Estado poderia até obrigar uma pessoa a praticar uma religião, mas não conseguiria impor à consciência individual uma crença verdadeira. $\mathrm{O}$ argumento da Inquisição era, sob esse aspecto, rejeitado por Locke, não por razões morais, mas por habilidade política, pois a seu ver, a imposição pela força de uma crença religiosa traria como consequiência um mau maior para a comunidade, que seria o aumento da hipocrisia civil. Por ter sua preocupação essencialmente voltada para os interesses da comunidade política, Locke entendia que a tolerância não deveria ser estendida às pessoas cujas convicções poderiam ameaçar as instituições; por exemplo, a tolerância no pensamento lockeano, não procurava garantir direitos civis para os ateus. Locke justificava a exclusão dos ateus dos benefícios do estado de direito sustentando o seguinte argumento: os ateus, por definição, não podiam jurar, pois não acreditavam em Deus, e, em consequiência, não se obrigavam em consciência a cumprir os acordos firmados, que constituíam o fundamento da sociedade civil.

$\mathrm{O}$ argumento desenvolvido por Pierre Bayle, no Commentaire Philosophique (1686), ${ }^{4}$ apresentou uma defesa teórica da tolerância, que retirou o problema do campo

\footnotetext{
${ }^{3}$ LOCKE, John. Carta sobre a Tolerância. Trad. João da Silva Gama. Lisboa: Edições 70, 1987
}

\footnotetext{
${ }^{4}$ BAYLE, Pierre. De La Tolerance. Commentaire Philosophique Presses Pocket, 1992.
} 


\section{Quaestio Iuris}

religioso. Bayle transferiu a questão para o âmbito da legislação moral, fruto do emprego da razão prática, independente da fé religiosa. O filósofo francês sustentava que as disputas provocadas por discordâncias teológicas poderiam encontrar solução no nível moral, onde a razão fala da mesma forma para todos os seres humanos. O pensamento de Bayle procurou estabelecer uma forma positiva de tolerância, baseada na relação entre a opinião e a sinceridade das pessoas na defesa de suas convicções. O erro do indivíduo, sob o ponto de vista de determinada convicção religiosa, não traria consigo a sua condenação ontológica, como sustentava a Inquisição; Bayle estabeleceu, assim, as raízes da tolerância moderna, que veio basear-se no direito à consciência errônea. A idéia da consciência errônea subverteu a concepção tradicional do cristianismo de que na mensagem, revelada pela Igreja Católica, encontrava-se a verdade última para o ser humano. Bayle procurou demonstrar que essa verdade poderia ser interpretada e encontrada por diferentes caminhos racionais, que seriam legitimados na medida em que se garantisse o direito inalienável do indivíduo em professar doutrinas consideradas por ele, em consciência, como verdadeiras. A liberdade de consciência aparece, assim, no pensamento de Bayle, como a mais alta expressão das relações entre o Homem e o seu Criador, e, por expressar esse vínculo, qualquer tentativa de controle clerical ou político da consciência individual seria considerado como um "estupro espiritual". 5 Ainda que referida à problemática religiosa, a teoria da tolerância de Bayle permitiu que se explicitasse racionalmente o papel da liberdade de consciência do indivíduo como o fundamento de uma sociedade, integrada por seres criados à imagem e semelhança do próprio Deus, tendo na razão o instrumento para fundamentar determinados direitos, que antecediam o Estado. Durante esse período, a tolerância representou uma atitude mais intelectual do que política, que procurava estabelecer normas para a coabitação pacífica entre católicos romanos e protestantes. Essa idéia à medida que se transferiu do campo religioso para o político, começou a ser empregada de forma extensiva, significando um princípio garantidor da convivência, não somente de credos religiosos diferentes, mas de convicções políticas divergentes. Essa nova concepção da tolerância é que foi considerada, pelos primeiros pensadores liberais, como sendo uma virtude social necessária para o funcionamento da ordem constitucional liberal. $\mathrm{O}$ advento do pensamento liberal trouxe consigo o entendimento

\footnotetext{
${ }^{5}$ LABROUSSE, Elizabeth. Pierre Bayle. Paris: Albin Michel, 1996.
} 
de que a tolerância passava a ser necessária não somente no campo das relações religiosas, mas principalmente nas relações políticas e civis.

Foi o filósofo inglês John Stuart Mill quem sistematizou os argumentos que estabeleciam as relações do conceito de tolerância com o de liberdade. $\mathrm{O}$ argumento justificador de Mill procurava atender à pergunta básica em seu pensamento: quais seriam os direitos que permitiriam ao homem conduzir livremente a sua vida? Mill identificou esses direitos como sendo aqueles que se originavam no exercício da autonomia individual; no princípio da autonomia individual face ao Estado, Mill situava o núcleo do argumento liberal em favor da tolerância. A autonomia individual no pensamento do filósofo inglês viria a expressar-se, preliminarmente, através do exercício do direito à opinião divergente. Em torno desse direito, Mill considerava a tolerância como a virtude social primordial para que fosse garantida a liberdade de opinião. A tolerância liberal, entretanto, restringia-se ao âmbito exclusivo da liberdade de opinião ${ }^{6}$, que garantiria para Mill a plena realização do princípio da autonomia. Não se tratava, portanto, de uma virtude aplicável ao exercício dos demais direitos e nem, muito menos, a indivíduos e grupos sociais que não participavam do sistema político.

A crise da tolerância no final do século XX deve ser inserida na interpretação tradicional de Mill e de como essa interpretação entrou em conflito com interesses e agentes sociais que surgiram no processo de democratização da sociedade liberal. Os desafios sociais e políticos que a ordem jurídica liberal encontrou, face aos problemas sociais e políticos das sociedades pluralistas e de massas do século XX, fizeram com que se explicitassem os limites da tolerância nos termos defendidos por Stuart Mill e pelos pensadores liberais de uma forma geral. A tolerância liberal revelou-se insuficiente para preencher a sua função de virtude política - destinada a garantir relações sociais e políticas igualitárias e estáveis - quando novas formas de intolerância entre grupos sociais e nações, provocadas por fatores étnicos, religiosos e políticos, começaram a ameaçar a própria sobrevivência da sociedade.

A história contemporânea obrigou à reformulação do conceito liberal de tolerância, fazendo com que o pensamento social revisse a idéia original de Mill, ampliando a sua abrangência ao demonstrar que existem laços necessários, não somente entre a tolerância e a liberdade, como principalmente entre a tolerância e o pluralismo religioso, cultural e político. Em outras palavras, constata-se uma explícita relação de

\footnotetext{
${ }^{6}$ MILL, John Stuart. On Liberty. Ed. Gertrud Himmelfarb. Harmondsworth, Penguin, 1978. p. 46 e segs.
} 


\section{Quaestio Iuris}

causa e efeito entre o pluralismo e a prática da tolerância, o que permite que se constate empiricamente como o crescimento da intolerância surge precisamente em sociedades onde se nega o pluralismo. ${ }^{7}$ Introduz-se dessa forma no debate sobre a tolerância a idéia da igualdade de valores e práticas políticas, sociais, culturais e religiosas diversas.

Desafiada precisamente pela diversidade dos conflitos étnicos, religiosos e políticos, a reflexão filosófica passou a procurar uma justificativa moral para a virtude da tolerância na sociedade democrática contemporânea. Duas respostas foram dadas para o problema, que, no lugar de solucioná-lo, serviram de argumento para agravar as situações de intolerância. Em primeiro lugar, desenvolveu-se o argumento totalitário que procura programar a crença na solução única e definitiva para as divergências morais e políticas, advogando o estabelecimento de uma ordem jurídica que terminava por consagrar a intolerância; o segundo tipo de resposta, nascida no seio do pensamento liberal, sustentava a incompatibilidade do regime democrático com a formalização jurídica da tolerância. Entre essas duas correntes doutrinárias que se opõem, mas que terminam, no que se refere ao tema da tolerância, por a negarem, o pensamento social contemporâneo tem procurado redefinir o conceito, com vistas à sua elaboração de maneira similar àquela empregada nos séculos XVI e XVII, tendo, entretanto, o objetivo comum de estabelecer a pax civilis.

O pensamento social contemporâneo procura, depois de reconhecer a importância funcional da idéia de tolerância para a prática política e a ordem jurídica, preencher o vazio que mina a expressão, provocado pelo relativismo e falta de convicções intelectuais na sociedade contemporânea, onde a tolerância acabou por significar o nivelamento comum de todas as idéias e convicções, como se todas tivessem o mesmo valor. Pensadores contemporâneos reagiram ao relativismo reinante, voltaram-se, como fizera Bayle, há quatro séculos, para a construção de um fundamento racional comum para a idéia. A convivência cívica estabelecida através do respeito aos outros em suas convicções, que consistia na idéia central do pensamento de Bayle, representou o passo inicial no processo de determinação de um conjunto de princípios válidos e eficientes para a solução dos problemas da atualidade.

\footnotetext{
7 MENDUS, Susan. Toleration and the Limits of Liberalism. Atlantic Highlands: Humanities Press International, 1989.
} 
Alguns autores, como Ricoeur, ${ }^{8}$ fizeram menção de duas fontes para um "programa prático de tolerância": a primeira é o princípio de abstenção ou da nãointervenção, do laissez-faire, apropriado ao estado liberal clássico, que se caracteriza pela indiferença na sua aplicação ao exercício dos direitos dos outros; a segunda fonte consiste, principalmente, no princípio da admissão - desconhecido nas formulações liberais - que deita as suas raízes no respeito aos direitos dos outros. A formulação do princípio da admissão insere-se no contexto de diferentes correntes da filosofia moral contemporânea, que buscam estabelecer critérios racionais e práticos para normatizar as relações sociais e, portanto, definir a ordem jurídica. Nesse contexto é que a tolerância recupera o seu sentido de virtude política, cuja sua utilização torna-se essencial para o funcionamento de uma ordem jurídica, fundada na liberdade, na igualdade e na solidariedade.

\section{Uma relação conflituosa}

A investigação sobre a natureza das relações da tolerância com a democracia tem levado muitos autores a descobrirem uma incompatibilidade entre os dois conceitos, chegando-se mesmo a afirmar que existe uma relação excludente entre a democracia e a tolerância. A argumentação que procura demonstrar esse conflito parte da tese de que a tolerância é somente uma idéia, tendo representado um importante papel na história dos direitos e da democracia, mas que na atualidade esgotou a sua função política e social. A tolerância seria então mais um ideal contingente, restrito na sua utilização a uma determinada época histórica, tendo sido útil no complexo processo de transição da ordem política medieval para a Idade Moderna. Exercido esse papel de princípio garantidor de um processo histórico-político, a tolerância perdeu, no entendimento desses autores, a sua utilidade, principalmente tendo-se em vista que o estado moderno nasce absolutista e depois se transforma em liberal, mas não em democrático. Por essa razão, a tolerância não pode ser considerada como um princípio constitucional, pois existe, preliminarmente, uma incompatibilidade entre a linguagem da tolerância e a dos direitos; assim sendo, considerar o princípio da tolerância como tendo um caráter central na democracia pluralista constitui, ao ver desses autores, um

\footnotetext{
${ }^{8}$ RICOUER, Paul. Em torno do político. Trad. Marcelo Perine. São Paulo: Edições Loyola, 1991. p. 174.
} 


\section{Quaestio Iuris}

sofisma do ponto-de-vista jurídico e político, pois a sua aplicação perde o sentido face à realidade da sociedade atual.

A defesa da tese acima esboçada baseia-se no entendimento de que a estrutura constitucional do estado contemporâneo caracteriza-se por sustentar-se em função de um conjunto de direitos e liberdades, que se reconhecem juridicamente na aceitação do

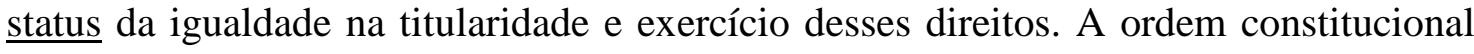
liberal parece, então, como suficiente para garantir a paz social e política, que representaram historicamente os objetivos últimos da prática do princípio da tolerância nos primórdios da Idade Moderna, pois a ordem jurídico-política liberal já incorporou a tolerância na sua formulação; na verdade, essa ordem tornou-se possível graças precisamente ao exercício e consagração constitucional do princípio da tolerância. Os críticos da possibilidade da tolerância integrar-se na prática democrática sustentam que se torna necessária a exclusão desse princípio da análise jurídico-política, pois somente assim a democracia deixa de correr o "risco alternativo", com que se depara, na medida em que a prática da tolerância pode levar ao relativismo ou a considerar-se a democracia como uma espécie de religião civil, restrita a alguns grupos sociais, onde não poderiam ser contempladas as múltiplas expressões etno-culturais que coexistem no seio da sociedade pluralista.

$\mathrm{O}$ argumento final refere-se à irrelevância da tolerância sob o ponto-de-vista jurídico, que procura mostrar como a estrutura jurídico-constitucional do estado liberaldemocrático não comporta a prática da tolerância. O princípio da tolerância não somente por ser histórico, mas também e principalmente por não encontrar uma expressão jurídica no arcabouço constitucional, torna-se, na opinião desses autores, irrelevante para o direito. A razão para tal afirmativa reside na constatação de que havendo um conflito entre o exercício da tolerância e a prática jurídica, o princípio da tolerância, por ser histórico e não sendo normatizado pela ordem jurídica, acaba esvaziado em suas possibilidades normativas, não servindo, portanto, para atender os objetivos últimos da ordem jurídico-constitucional. A análise dos elementos caracterizadores da tolerância liberal (a assimetria nas relações entre indivíduos e grupos sociais, a superioridade de quem tolera a contradição entre a ordem normativa positivada e a ordem normativa tolerante e a ausência de garantias jurídicas, a não ser a

\footnotetext{
${ }^{9}$ PARAMO, Juan Ramón. Tolerância y Liberalismo. Madrid: Centro de Estúdios Constitucionales, 1993. p. 51 e segs.
} 
vontade do tolerante) retrata com fidelidade como os mecanismos políticos e sociais da sociedade liberal-burguesa provocam uma dinâmica geradora de exclusão social.

Nesse contexto, é que se desenvolveu a idéia de que a tolerância serviu exclusivamente como argumento em determinado momento da história do estado moderno; mas o Estado Liberal, nascido sob a sua inspiração, trouxe consigo o seguinte paradoxo: a tolerância liberal ao admitir a presença daquele que se trata de tolerar, considera o tolerado como um mal em relação aos valores sociais comuns, mas que em circunstâncias de crise e ameaça à sobrevivência da sociedade deve ser tolerado. Essa exclusão latente na prática política liberal deita suas raízes na própria concepção de cidadão no liberalismo, pois a autonomia individual, ainda que admitida na teoria, na prática social somente é reconhecida naquele que compartilha laços sociais comuns, definidos em termos religiosos, lingüísticos e étnicos. Percebe-se, portanto, como o paradoxo liberal segrega o vírus da exclusão social e, em última análise, da intolerância.

As dificuldades no entendimento da função da tolerância na modernidade aparecem, também, na teoria social e política. A teoria contemporânea da justiça, desenvolvida principalmente por John Rawls, contempla a tolerância com um lugar relevante, considerando-a como uma virtude política relativa à equidade. $\mathrm{O}$ argumento central de Rawls, no que se refere à tolerância, parte da constatação de que as democracias liberais contemporâneas caracterizam-se por serem pluralistas, onde coexistem uma pluralidade de concepções do bem; o Estado nesse contexto não pode empregar a força para impor os valores ou crenças da maioria aos grupos minoritários. O princípio da tolerância imprime à ação do poder público a necessária neutralidade face aos valores e práticas religiosas, morais e estéticas, que não sejam compartilhadas pela maioria da coletividade. A teoria política e social rawlsiana avança em relação à concepção original da tolerância, pois incorpora na teoria da justiça a idéia de que além das convicções religiosas, o Estado deve ficar neutro diante dos conflitos a respeito da moral que aparecem na sociedade pluralista.

Os autores clássicos do liberalismo no século XVIII e nas primeiras décadas do século XIX afirmavam - e encontramos nessa postura a explicação para a redução da idéia da tolerância à sua função histórica, isto é, a tolerância não tinha mais razão de ser, pois já se encontrava reconhecida nas declarações universais dos direitos do 
homem e do cidadão. Thomas Paine escreveu a propósito da Constituição francesa de 1791: ${ }^{10}$

[...] a Constituição francesa renunciou à tolerância como à intolerância e estabeleceu um DIREITO DE CONSCIÊNCIA UNIVERSAL. A tolerância não é mais o contrário da intolerância; ela é sòmente a sua contrafação. Todas as duas são despóticas; uma se arroga o direito de proibir a liberdade de consciência, a outra a de concedê-la. Uma é como um papa brandindo o fogo e a lenha, o outro como um pontífice vendendo ou concedendo indulgências. A primeira representa a Igreja e o Estado, a segunda a Igreja e o tráfico.

Os direitos reconhecidos pelas constituições liberais referem-se, entretanto, a direitos do indivíduo, que não se encontram no espaço público, mas no espaço privado. As liberdades do espaço privado acham-se suficientemente protegidas pela ordem jurídica liberal, sendo que a tolerância no espaço público ou político não encontra guarida no universo intelectual dos autores liberais. Assim, por exemplo, Voltaire afirmava que o dogmatismo e a intolerância, em virtude de motivos religiosos eram irracionais e condenáveis, enquanto que a intolerância justificada por razões de ordem política ou de segurança poderia ser aceita. ${ }^{11}$ A tolerância liberal, portanto, referia-se a um tipo de liberdade, a liberdade religiosa e a de expressão, não contemplando as demais situações sociais e políticas do indivíduo, considerado $\underline{\text { in abstracto }}$ e desvinculado da realidade social objetiva em que se encontra inserido.

Nos regimes liberais, a questão da tolerância foi teoricamente resolvida, pois tendo sido consagrada no texto da lei, presume-se que se encontra plenamente consagrada nos direitos definidos pelo próprio texto da lei, não cabendo a sua aplicação naquelas situações, que não tenham tido a previsão legal. A teoria da justiça de Rawls ao avançar na reflexão sobre a tolerância levou-a, entretanto, para um novo impasse. Enquanto o liberalismo clássico proclamava a tolerância como própria do espaço privado, ainda que com $\underline{\text { status }}$ constitucional, Rawls deslocou o debate para o âmbito da distribuição eqüitativa dos custos e vantagens na sociedade, que definirão uma sociedade justa. Rawls procurou responder os problemas que surgiram no seio da sociedade contemporânea, mas que não foram respondidos pela ordem jurídica liberal, estabelecendo para isso critérios a serem observados na distribuição de bens e encargos sociais. O núcleo do pensamento rawlsiano sobre a distribuição eqüitativa dos bens encontra-se no pressuposto de quem será o sujeito de direito na sociedade. A escolha implícita de Rawls consiste em admitir como sujeito de direito o cidadão do estado

\footnotetext{
${ }^{10}$ PAINE, Thomas. The Rights of Man. New York: Dolphin Books, 1961. p. 323-324.

${ }^{11}$ VOLTAIRE, Tratado sobre a Tolerância. São Paulo: Martins Fontes, 1993.
} 
liberal, ou seja, aquele que pode participar do jogo político como eleitor e representante político. As constituições liberais, principalmente as do século passado, como a Constituição brasileira de 1824, estabelecem essa definição legal do cidadão, vinculando-a à renda pessoal.

A mesma linha de argumentação, na qual o sujeito de direito já se encontra definido, isto é, trata-se do cidadão reconhecido pela ordem constitucional liberal, serve, também, como pressuposto na teoria de Michael Walzer (1983). As "esferas da justiça" constituem espaços onde a distribuição de bens implica no reconhecimento de fronteiras, que logicamente admitem a existência de incluídos e excluídos. Em torno dessa definição constitucional dos incluídos processa-se o debate contemporâneo, ainda que a aceitação do pressuposto de que não há exclusão quando a ordem jurídica não se refere explicitamente a indivíduos e grupos, e afaste da análise aqueles que a prática social, política e jurídica exclui dos benefícios da sociedade moderna.

\section{As aporias da tolerância liberal}

Os dois blocos de argumentos críticos à tolerância na modernidade, que foram acima explicitados - o político-jurídico e o social - padecem, entretanto, das mesmas insuficiências analíticas; ambos acham-se prisioneiros de uma interpretação reducionista do princípio da tolerância, que consiste em privilegiar o seu papel histórico e considerá-lo irrelevante no estado democrático de direito. Ainda que o princípio da tolerância tenha tido uma aplicação histórica, a permanência do tema mostra como a solução liberal torna-se insatisfatória e insuficiente para solucionar os problemas suscitados na sociedade contemporânea. O entendimento de que se torna necessário repensar o problema supõe que se leve em consideração as características dessa ordem política e jurídica liberal, que proclama um sistema de direitos, mas não soluciona os problemas das novas formas de intolerância. Dentro da ordem liberal ocorrem situações de inclusão e exclusão, que obrigam a teoria da justiça a considerar esses casos limites, pois eles evidenciam exatamente os desafios centrais com que se defronta o estado liberal.

A questão nuclear parece ser a da definição dos sujeitos de direito, para além da dogmática da ordem jurídica liberal. Essa questão que não foi suficientemente 
elaborada por teóricos como Ralws, ${ }^{12}$ Ackerman, ${ }^{13}$ Nozick, ${ }^{14}$ e Raz, ${ }^{15}$ torna-se fundamental para que se tenha uma apreciação objetiva e não teórica e abstrata da tolerância. Isto porque não se trata mais de problemas que poderão ser resolvidos no quadro das convicções individuais e, portanto, no espaço privado, pois envolvem a aceitação de diferenças entre grupos sociais, relativas à distribuição de bens e ao acesso às garantias jurídicas do estado democrático de direito; sob esse ponto-de-vista, pode-se dizer que a teoria constitucional do estado de direito ressente-se precisamente de uma reflexão sistemática sobre a justiça, que se fundamente nos fatos sociais da exclusão, da discriminação e da opressão no espaço público. A lógica constitucional liberal passa ao largo dessa questão, pois ela tergiversa e não afirma quais as obrigações de uma sociedade política diante daqueles que não se acham política e socialmente integrados. $^{16}$

A questão da definição do sujeito de direito permite que se tenha uma abordagem do problema da tolerância na sociedade contemporânea sob um ângulo que leve em consideração quais os indivíduos - e as razões pelas quais - são excluídos na sociedade. Trata-se de analisar quais são as justificativas morais, que procuram legitimar o tratamento diferenciado dado a alguns indivíduos no espaço público. Essa argumentação remete-nos à análise da questão da igualdade, o que permite que se dimensione a verdadeira dimensão da intolerância, expressa na exclusão da ordem política e jurídica daqueles que se diferenciam da maioria da sociedade, seja por motivos culturais ou sociais. A tolerância não como equidade, mas como igualdade, acaba constituindo-se em parâmetro objetivo para a democracia, pois perpassa todas as políticas sociais que pretendem no estado liberal realizar a justiça social. Para isto, no entanto, é necessário estabelecer princípios racionais que permitam a definição de uma ordem jurídica e informem o intérprete na sua aplicação. Esses princípios deverão resultar de um processo no qual o intérprete parta da experiência empírica para a formulação teórica e venha, desta última, para a práxis jurídica.

\footnotetext{
${ }^{12}$ RAWLS, John. A Theory of Justice. Massachusetts: Harvard University Press, 1972.

${ }^{13}$ ACKERMAN, Bruce A., Social Justice in the Liberal State. New Haven: Yale University Press, 1980.

${ }^{14}$ NOZICK, Robert. Anarchy, State, and Utopia. Oxford: Basil Blackwell, 1974.

${ }^{15}$ RAZ, Joseph. The Morality of Freedom. Oxford: Clarendon Press, 1990.

${ }^{16}$ GALEOTTI, Anna Elisabetta. "Tolérance et justice sociale”, In: Pluralisme et Équité. Paris: Éditions Esprit, 1995. p. 116.
} 
A tolerância no final do século XX refere-se, principalmente, a dois tipos de problemas, que em certas circunstâncias políticas e sociais podem ocorrer de forma simultânea: a tolerância política, que tem a ver com a aceitação numa determinada ordem política de convicções ideológicas e crenças partidárias diferenciadas, característica da sociedade liberal; e a tolerância social, relativa à convivência numa mesma sociedade política de comunidades culturalmente e economicamente diferenciadas, própria das sociedades democráticas e pluralistas. Em ambos os casos, o direito tem uma função específica, podendo servir como fonte de correção de situações desiguais e injustas, ou então legalizando diferentes formas de opressão. O dilema da ordem jurídica democrática consiste, precisamente, na incorporação dessas duas dimensões da tolerância na formulação e na aplicação da norma jurídica, como procuraremos demonstrar.

As relações da tolerância com a ordem jurídica supõem, necessariamente, o entendimento da mudança da natureza da tolerância em virtude dos problemas, originados no seio da sociedade complexa da atualidade. A ordem jurídica liberal, que tinha na tolerância política o pressuposto implícito para o seu funcionamento, demonstrou durante o século $\mathrm{XX}$ a sua incapacidade em lidar com problemas que escapavam da lógica interna do modelo liberal; tornou-se, assim, necessário a elaboração de uma ordem jurídica que pudesse estabelecer normas para as novas relações sociais e culturais e que fosse ativada por um novo tipo de tolerância, que não encontrava respaldo nos quadros do estado liberal clássico. A crise que se observa em diferentes países, como França, Estados Unidos e Alemanha, provocada por políticas públicas relacionadas com minorias étnicas e religiosas, deitam, provavelmente, as suas raízes na tentativa de aplicação do direito liberal - onde as relações sociais e culturais têm como uma de suas características o envolvimento de reduzido número de agentes sociais - à sociedade complexa da atualidade, que supõe para o seu funcionamento o concurso de vários e conflitantes agentes sociais.

Não se trata, portanto, mais e exclusivamente, da aceitação da tolerância liberal, que solucionava os conflitos nos limites do estado constitucional de direito, considerando na práxis jurídica as relações sociais, os grupos e os indivíduos, que não se enquadravam logicamente nas previsões legais, como fora do âmbito e da proteção da ordem social e jurídica, e, portanto, passíveis de punição em nome da sobrevivência da sociedade; agregou-se, assim, ao tema central do debate na sociedade liberal, ou seja, o 
da liberdade de opinião, a questão da tolerância como aceitação de diferentes culturas e valores pela sociedade e pelo estado democrático. O processo de democratização do estado liberal refletiu-se não somente na participação de novos agentes sociais no sistema de poder, mas também no reflexo que essa participação trouxe para a ordem jurídica, que passou a contemplar demandas e proclamar direitos que pretendem assegurar a participação política e o acesso aos benefícios da sociedade de grupos sociais até então excluídos. A juridificação ocorrida não garantiu, entretanto, a implementação dessa nova ordem jurídica, que, muitas vezes, estabelece direitos e garantias nos textos legais, mas não os implementa nas políticas públicas e nas decisões judiciais.

O processo de globalização da economia trouxe consigo um elenco de novos desafios, que não se limitaram, exclusivamente, à discussão dos limites legais à livre circulação de idéias e opiniões; os problemas provocados pela pobreza e as diferenças culturais mostraram como os chamados direitos sociais entraram em conflito com os direitos básicos do estado liberal clássico, principalmente o direito de propriedade, na sua concepção clássica, e não se inseriram na estrutura lógica do regime jurídico liberal. Esses direitos sociais no primeiro momento do processo de democratização do estado liberal surgiram mais como formas jurídicas desse processo, custando em muitos países, como é o caso do Brasil, a efetivar-se na prática do direito.

\section{A ordem legal e o véu da intolerância}

Na América Latina, ainda que existam em alguns países formas de intolerância étnico-cultural, a ordem jurídica não prevê abertamente a exclusão. A intolerância relaciona-se mais com as grandes desigualdades econômicas e sociais, o que pode se constatado no campo do direito, principalmente, em dois tipos de situação: na discriminação legal, que se produz através da prática jurídica que tem como conseqüência diferentes tipos de exclusão social, consagrando comportamentos sociais eivados de intolerância; o segundo tipo ocorre quando o sistema jurídico legaliza e, em última análise, consagra a exclusão social, através da impunidade.

Em ambos os casos, o sistema jurídico funciona dentro de rígidos parâmetros de legalidade, sendo esta empregada para consagrar precisamente situações de exclusão, que deveriam ser corrigidas pela própria lei. O legalismo, que se caracteriza como o 


\section{Quaestio Iuris}

culto exacerbado e imobilizador da lei, não deve ser confundido, entretanto, com o devido respeito ao princípio da legalidade. Ao contrário, na prática o judiciário, em muitos casos, por encontrar-se prisioneiro da interpretação restrita da lei, acaba transformando-se na fonte da discriminação social e da intolerância. A característica fundamental desse tipo de processo de aplicação da lei reside na ausência de qualquer consideração sobre as conseqüências sociais das decisões judiciais, que leve em consideração os diferentes interesses e expectativas da sociedade. Ainda que o argumento legalista, que procura justificar esse tipo de aplicação da lei sustente a sua fidelidade ao princípio da legalidade - caracterizado pela generalização igualitária da lei - o que se revela, muitas vezes, na práxis jurídica é o caráter subjetivo, que se revela discriminatório, do procedimento legal. A questão fundamental nesse processo judicial distorcido reside na falta de acesso à justiça em termos de igualdade, que garanta direitos proclamados na constituição e nas leis; ocorre, portanto, um caso evidente de “exclusão social" através da aplicação do direito.

A conseqüência social desse tipo de legalismo consiste em excluir pessoas e grupos sociais do sistema, sendo que esses segmentos sociais somente são considerados como agentes sociais quando enquadráveis pelo sistema legal na categoria de devedores, incriminados, culpados ou suspeitos. Em princípio, aqueles que por circunstâncias sociais e culturais não participam dos benefícios e garantias do sistema são considerados sujeitos de direito na medida em que têm somente deveres em relação à sociedade e nenhum direito. Verifica-se, então, como na tradição jurídica latinoamericana, baseada nos processos inquisitoriais herdados da Inquisição, e no legalismo positivista, que a aplicação do princípio da legalidade termina em muitos casos por criar, como diria Orwell, indivíduos mais iguais do que outros.

A aplicação distorcida do princípio da igualdade faz com que outra situação social esteja presente nos países da América Latina. Trata-se da questão da impunidade, que explica como nas relações do Direito com a sociedade as penas aplicadas pelo sistema judiciário não representam segurança para a comunidade, além de esvaziar o sentido simbólico da ordem jurídica na sua função de garantir a estabilidade das relações sociais. $\mathrm{Na}$ área criminal, principalmente, a condenação dos desigualmente favorecidos não garante punição e, muitas vezes, serve de motivo para a consecução de outros crimes; o caso de policiais culpados que terminam por facilidades do processo não cumprindo pena, mas que se voltam contra suas vítimas e seus familiares para um 


\section{Quaestio Iuris}

vol.05, $\mathrm{n}^{\circ}$ 01. ISSN 1516-0351

ajuste de contas, mostra como a impunidade é uma das fontes geradoras da intolerância. Isto porque a não-punição representa uma dupla violação dos direitos da vítima, que são desrespeitados pelo ato de violência e, novamente, quando seus agressores escapam da punição em virtude de interpretações legalistas, que encobrem o corporativismo policial ou a solidariedade de classe.

A leniência face ao fato criminoso impossibilita a convivência social fundada na tolerância, ficando a ordem jurídica privada da sua principal virtude, que lhe garante o estabelecimento de relações de respeito mútuo de direitos e deveres. Ao lado desses aspectos, a impunidade faz com que indivíduos que pertencem a grupos de privilegiados, politicamente ou socialmente, não necessitem comportar-se prevendo as suas ações, como devem comportar-se os cidadãos de um estado de direito, onde os direitos e deveres encontram-se previstos na lei; os recentes exemplos da ação policial em diversos estados brasileiros, quando policiais continuam a trabalhar nas ruas, mesmo tendo respondido a processos que indicavam um comportamento arbitrário e violento, mostram o caráter perverso desses sistemas jurídicos. A impunidade, consequiência de um sistema legal corporativista que submete o policial infrator ao julgamento de seus pares e não da justiça comum, permite a reincidência criminosa e fomenta a intolerância em relação aos mais fracos socialmente, ocorrendo, então, a quebra da ordem jurídica.

As causas para as distorções encontradas na aplicação do direito nos países latino-americanos encontram-se na sobrevivência de uma cultura inquisitorial nos meios jurídicos. As características teóricas dessa cultura, comum na maioria dos países latinoamericanos, podem ser reunidas em quatro grupos:

a) a mentalidade formalística, que acredita poderem ser resolvidos os conflitos individuais e intergrupais através de certas formalidades processuais;

b) o esoterismo das normas jurídicas, que fazem com que a maioria da população permaneça distanciada da linguagem e da realidade judiciária;

c) o burocratismo ou a obsessão pelo procedimento, fazendo com que o ato de julgar esteja mais preocupado com o formalismo legal do que com a questão substantiva geradora do conflito;

d) a santidade mítica do sistema judiciário, onde o juiz aparece como sendo o defensor dos princípios do bem contra o mal e, portanto, acima do controle político da sociedade. 
A cultura inquisitorial tem consequiências práticas, que se revelam nas diferentes crises do sistema judiciário latino-americano, geradoras de injustiças, opressões e desigualdades:

a) a crise da eficiência, que se evidencia no fracasso do sistema policial e judiciário na ação contra o crime e na lentidão na solução das causas civis;

b) a crise da impunidade, conseqüência da primeira crise, onde a impunidade dos poderosos desnuda a idéia que perpassa toda a cultura inquisitorial: não existe igualdade na responsabilidade civil e penal;

c) a crise dos direitos humanos, constatada na prática costumeira de torturas, nas execuções sumárias, no fato de cidadãos serem mantidos presos sem condenação, na ausência de advogados de defesa, etc.;

d) a crise da legitimidade, que se expressa na descrença do povo no sistema judiciário, como se tem evidenciado nas mais recentes pesquisas de opinião.

\section{A guisa de conclusão: tolerância e estado democrático de direito}

A questão da tolerância nos sistemas jurídicos de tradição positivista refere-se, portanto, ao estabelecimento de alguns princípios que possam servir de guias para o aplicador da lei, superando a síndrome inquisitorial do sistema. Quando a Constituição estabelece os princípios e os objetivos do estado democrático de direito, desenha-se um quadro político e social, que se diferencia essencialmente do estado liberal democrático. Os princípios expressos pelo legislador constituinte somente adquirem sentido lógico, na medida em que se aceitar o sistema jurídico do estado democrático de direito comprometido, tanto com as liberdades negativas, como com as liberdades positivas ${ }^{17}$.

A sugestão de Paul Ricoeur de que as duas faces da liberdade devem ser entendidas como dois princípios, quando relacionadas com a virtude da tolerância, permite que esta assuma então um caráter positivo e não somente passivo, como ocorria na sociedade liberal-burguesa: o sentido da tolerância positiva consiste em agregar ao dever de não - fazer e de não-interferência do Estado, o reconhecimento do direito de existência e de expressão de diferentes grupos sociais e culturais. Nas palavras do

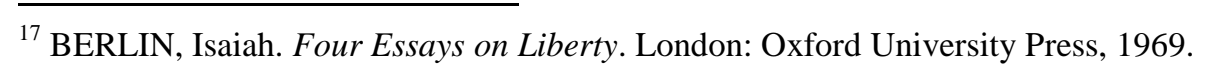




\section{Quaestio Iuris}

filósofo francês: do princípio da abstenção começamos a construir o princípio da inclusão ou admissão.

Em torno do princípio da inclusão é que se pode fazer uma análise sobre a natureza da tolerância no estado democrático e pluralista. Isto porque a tolerância é a virtude que pode assegurar à ordem jurídica a integração de direitos e liberdades de indivíduos e grupos sociais excluídos; a ordem jurídica que se fecha no culto do fetichismo legal torna-se excludente, pois rejeita aqueles que são excluídos da sociedade e permite a construção de guetos de intolerância. ${ }^{18}$ A dimensão democrática da nova tolerância realiza-se, assim, na admissão no texto da lei e na prática jurídica daqueles que são considerados socialmente excluídos, mas que na verdade fazem parte da comunidade cívica da nação.

O papel da tolerância na superação dos limites da lei na ordem liberal insere-se, por outro lado, no entendimento da natureza e das relações da sociedade pluralista com essa virtude política. Na medida em que se possa contextualizar a sociedade é que se poderá definir o tipo específico de tolerância a que estamos fazendo referência; por essa razão, para cada concepção ou defesa de um tipo de pluralismo, existe um correspondente tipo de tolerância. ${ }^{19} \mathrm{Na}$ sociedade moderna, pós-medieval, quando se estruturou o estado moderno, a tolerância e, portanto, a aceitação de valores divergentes do credo oficial, eram um mal necessário, aceito inclusive no seio das monarquias absolutistas; destinava-se, como propunha-se o Edito de Nantes (1598), a salvar a sociedade da desintegração política. A tolerância liberal, por sua vez, definia-se pelo viver e deixar viver estabelecido pelas leis do mercado, sendo no fundo o reconhecimento do direito à existência de interesses opostos na sociedade. A tolerância que constitui uma qualidade da sociedade pluralista da atualidade tem, entretanto, como espinha dorsal, não somente a aceitação de valores e interesses divergentes, mas sobretudo o incentivo à diversidade de grupos sociais primários, que se integram no processo de funcionamento e controle da sociedade.

Trata-se, portanto, de estabelecer um conceito de tolerância que seja uma virtude da sociedade pluralista e democrática. Enquanto o pluralismo liberal identificava-se

\footnotetext{
18 NEVES, Marcelo. Legalismo e impunidade: intolerância e permissividade jurídicas na América Latina. Rio de Janeiro, UNESCO/ UFRJ, mmo, 1994.

${ }^{19}$ WOLFF, Robert Paul. "Beyond Tolerance", In: Wolff, Robert Paul, Barrington Moore Jr. e Marcuse, Herbert. A Critique of Pure Tolerance. London: Jonathan Cape, 1969.
} 


\section{Quaestio Iuris}

com a fórmula da democracia liberal clássica - one man - one vote -, o pluralismo democrático contemporâneo tronou-se um instrumento moral neutro que afirma a necessidade de cada grupo ter a sua parte no todo social. A pergunta que foi respondida negativamente pelos liberais de que haveria uma discordância fundamental entre tolerância e pluralismo liberal, aparece na atualidade como condição mesma de sobrevivência da sociedade. Nesse sentido é que se torna necessário, na aplicação da lei, um entendimento que se situe para além da lógica constitucional restrita. Destaca-se, assim, o papel do judiciário na interpretação da "verdade legal", ${ }^{20}$ que se encontra para além do texto positivado.

Os exemplos dos países latino-americanos demonstram que o princípio da inclusão na aplicação da lei constitui um instrumento a ser usado pelos juízes, com vistas a contribuir para diminuir a desigualdade social e, também, eliminar os focos de intolerância. A inclusão, entretanto, somente torna-se um princípio na medida em que, na aplicação do texto legal, tenha-se presente que será utilizado no sentido de aperfeiçoar a ordem social face às mudanças constantes de uma sociedade complexa. $\mathrm{O}$ compromisso com esse aperfeiçoamento encontra-se inserido nos fundamentos morais da ordem constitucional que somente explicitou de forma necessariamente parcial os valores fundamentais da sociedade e do estado.

O ponto nodal da questão reside, certamente, na incorporação da temática da inclusão social na ordem constitucional. O estado democrático de direito deslocou a questão, rompendo o círculo vicioso do constitucionalismo liberal, que considerava a inclusão social em termos de liberdade igual, situando-a sob o ângulo restrito da proclamação de uma igualdade jurídica teórica entre os indivíduos e ignorando as distorções na distribuição equânime de bens. Nesse sentido é que Galeotti escreveu: “essas circunstâncias [a manifestação de diferenças sociais entre grupos] são cruciais, pois elas tornam as questões da tolerância diretamente dependentes da realização da justiça social e do progresso em direção à igualdade de consideração, que considero profundamente como mais fundamental do que a igualdade econômica"21 (grifo nosso). A tolerância torna-se dessa forma uma virtude política essencial para a realização dos objetivos últimos do estado democrático de direito e, como tal, faz parte integrante do arcabouço hermenêutico na aplicação da lei.

\footnotetext{
${ }^{20}$ FAGUNDES, Seabra. $O$ controle dos atos administrativos pelo poder judiciário. Rio de Janeiro: José Kofino Editor, 1991.

${ }^{21}$ GALEOTTI, Anna Elisabetta. op. cit. p. 119.
} 


\section{Quaestio Iuris}

Como chama a atenção Garapon $^{22}$ a metamorfose da idéia da tolerância tem a ver com a mudança ocorrida no sistema político, quando a monarquia absoluta fundada na fé religiosa transformou-se no estado de direito baseado numa nova concepção de justiça. A justiça, tanto no quadro do absolutismo, quanto no estado liberal de direito e, principalmente, no estado democrático de direito, é o referencial último; ela, entretanto, não tem o mesmo sentido, pois deixou de ter um conteúdo substancial e passou a ser definida em termos mais procedimentais. "Diante da lei”, escreve Paul Ricoeur, "os indivíduos são reputados ter crenças, convicções, interesses, que definem o conteúdo que a justiça ignora, porque ela é a justiça, isto é o árbitro de pretensões rivais, não o tribunal da verdade". ${ }^{23}$

\section{Referências}

ACKERMAN, Bruce A., Social Justice in the Liberal State. New Haven: Yale University Press, 1980.

BAYLE, Pierre. De La Tolerance. Commentaire Philosophique. Presses Pocket, 1992.

BERLIN, Isaiah. Four Essays on Liberty. London: Oxford University Press, 1969.

CHRISTIN, Olivier. La Paix de Religion, l'autonomisation de la raison politique au XVI e. siécle. Paris: Seuil, 1997.

FAGUNDES, Seabra. O controle dos atos administrativos pelo Poder Judiciário. Rio de Janeiro: José Kofino Editor, 1991.

GALEOTTI, Anna Elisabetta. "Tolérance et justice sociale”, In: Pluralisme et Équité. Paris: Éditions Esprit, 1995.

GARAPON, Antoine. "Le droit, nouveau langage de la tolérance", In: Diogène, 176, oct.-dec. 1996.

LABROUSSE, Elizabeth. Pierre Bayle. Paris: Albin Michel, 1996.

LOCKE, John. Carta sobre a Tolerância. Lisboa: Edições 70, 1987

MENDUS, Susan. Toleration and the Limits of Liberalism. Atlantic Highlands: Humanities Press International, 1989.

\footnotetext{
${ }^{22}$ GARAPON, Antoine. "Le droit, nouveau langage de la tolérance”, In: Diogène, 176, oct.-dec. 1996.

${ }^{23}$ RICOUER, Paul. Lectures 1. Paris: Editions du Seuil, 1991. p. 300.
} 
MILL, John Stuart. On Liberty. Ed. Gertrud Himmelfarb. Harmondsworth, Penguin, 1978.

NEVES, Marcelo. Legalismo e impunidade: intolerância e permissividade jurídicas na América Latina. Rio de Janeiro, UNESCO/ UFRJ, 1994.

NOZICK, Robert. Anarchy, State, and Utopia. Oxford: Basil Blackwell, 1974.

PAINE, Thomas. The Rights of Man. New York: Dolphin Books, 1961.

PARAMO, Juan Ramón. Tolerância y Liberalismo. Madrid: Centro de Estúdios Constitucionales, 1993.

RAWLS, John. A Theory of Justice. Massachusetts: Harvard University Press, 1972.

RAZ, Joseph. The Morality of Freedom. Oxford: Clarendon Press, 1990.

RICOUER, Paul. Em torno do político. São Paulo: Edições Loyola, 1991.

RICOUER, Paul. Lectures 1. Paris: Editions du Seuil, 1991.

VOLTAIRE, Tratado sobre a Tolerância. São Paulo: Martins Fontes, 1993.

WOLFF, Robert Paul. "Beyond Tolerance", In: Wolff, Robert Paul, Barrington Moore Jr. e Marcuse, Herbert. A Critique of Pure Tolerance. London: Jonathan Cape, 1969. 